\title{
Prevalence, aetiology, and care of severe and profound hearing loss
}

Marie-Florence Baille, Catherine Arnaud, Christine Cans, Hélène Grandjean, Christiane du Mazaubrun, Claude Rumeau-Rouquette

\begin{abstract}
Severe and profound hearing loss $(>70$ dB) were analysed in a retrospective study of 226 children, born between 1976 and 1985, and recruited from three French administrative departments. The prevalence was 0.54 per 1000 children under 9 years old, with no decrease over the study period. A hereditary origin was identified in $20.8 \%$ of cases and an infectious origin in $11.5 \%$. Perinatal risk factors were present in $11.5 \%$, while the aetiology was undetermined in more than half the cases. In $85.8 \%$ of the children there was no other severe impairment. Marked learning difficulties were observed: $36 \%$ of the children were two years behind their age group and $28 \%$ were more than two years behind. The age of initial care decreased over the study period but is still too advanced. Systematic neonatal screening would enable earlier care, which should limit the social and educational impact of hearing loss.

(Arch Dis Child 1996;75:129-132)
\end{abstract}

Keywords: hearing loss, prevalence, aetiology, care.

In attempts to improve the management of childhood disabilities, it is important to have information on their prevalence and to establish their aetiology. Much useful information can be obtained from registry data, ${ }^{1-3}$ and, although there are several registers for cerebral palsy, only a few have been set up for sensory and especially auditory deficits. Another source of information derives from prospective ${ }^{45}$ or retrospective studies. ${ }^{6}{ }^{7}$ In France, the incidence of severe deficits has been evaluated in a population survey carried out over three generations of children born in 1972, 1976, and $1981 .^{8}$ The results indicated a fall in the incidence of hearing loss between 1976 and 1981. We report here a new study of severe and profound hearing loss in children born between 1976 and 1985 recruited from three French administrative departments, in order to describe more recent evolution and to analyse aetiology and management. Women and Children's

Health, INSERM

Paris, France

C du Mazaubrun

C Rumeau-Rouquette

Correspondence to:

CJF 94-06, CHU La Grave,

CJF 94-06, CHU La Grave

France.

Accepted 30 April 1996 were obtained from a retrospective survey of severe disabilities in children carried out between 1992 and 1993 in three French departments (Haute-Garonne, Isère, Saône et
Loire). This involved all disabled children born between 1976 and 1985 whose parents resided in the three departments.

The medical and care data were all obtained from the records of the CDES (Commissions Départementales d'Education Spéciales), the sole official organisation in France dealing with the guidance, treatment, and care of handicapped children (Law of 30/6/1975 for the Guidance of Handicapped Persons). Previous studies $^{8}$ have indicated that the CDES data are exhaustive for children of school age with severe deficits.

We analysed all cases of children with bilateral severe and profound hearing loss (hearing loss $>70 \mathrm{~dB}$ in the best ear) as laid down in the International classification of impairments, disabilities and handicaps. ${ }^{9}$ Inclusion was determined by the results of pure tone audiometry. Two hundred and twenty six children were included whose parents gave their consent for examination of the relevant CDES records.

As the children born in 1985 were 8 years old at the time of data collection, we included for the prevalence study only those children under 9 years of age on first registration with the CDES. The number of cases was related to the total number of children born the same year and residing in the same department (prevalence per 1000 resident children) given in the last National Census (1990) ( $\mathrm{n}=$ 327095 births). We also calculated the prevalence for children born and residing in each of the three departments (prevalence per 1000 of born and residing children; 1990 National Census: $n=231571$ ).

The children were given care either as outpatients or as full or half-time residents in specialised centres. Care included educational and psychological assistance, speech therapy, teaching sign language, psychotherapy and physiotherapy in cases with associated impairments, and even full schooling in certain cases.

School achievement was evaluated for the children aged 6 years and over, 6 years being the age of compulsory schooling in France. Educational retardation could be calculated only for the children of 6 years and over who attended kindergarten (ages 3 to 5) and primary school (ages 6 to 10). The data were not sufficiently accurate for the other children

The data were analysed using PCSM (Deltasoft, Meylan, France) and EPI-INFO (CDC, Atlanta, USA). The incidence rates were compared using the $\chi^{2}$ test, the trend with time was analysed using the $\chi^{2}$ test for linear tendency and

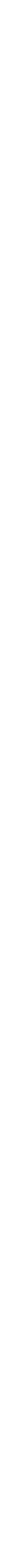


Table 1 Prevalence of severe and/or profound hearing loss per 1000 resident children and per 1000 children born and residing in three French departments. All children were less than 9 years of age

\begin{tabular}{|c|c|c|c|c|}
\hline & Haute-Garonne & Isère & Saône et Loire & Total \\
\hline \multicolumn{5}{|c|}{ Children residing in the departments } \\
\hline Total number ${ }^{1}$ & 108461 & 145633 & 73001 & 327095 \\
\hline Number of hearing impaired & 83 & 91 & 43 & 217 \\
\hline Prevalence & $0.77^{\star}$ & 0.62 & 0.59 & 0.66 \\
\hline \multicolumn{5}{|c|}{ Children born and residing in the departments } \\
\hline Total number ${ }^{1}$ & 79320 & 97672 & 54579 & 231571 \\
\hline Number of hearing impaired & 38 & 56 & 31 & 125 \\
\hline Prevalence & $0.48^{\star}$ & 0.57 & 0.57 & 0.54 \\
\hline
\end{tabular}

${ }^{1} 1990$ National Census figures.

$\star$ Significant difference between two prevalences $(p<0.05)$.

the correlation coefficient $(r)$. Mean values were subjected to analysis of variance.

\section{Results}

For the three departments, we analysed the data on 226 children born between 1976 and 1985 and aged between 6 and 16 years at the time of the study. There was a slight, non-significant male dominance $(52.5 \%$ boys, $47.6 \%$ girls). The majority of the children in this population presented an isolated hearing deficit (194 cases, 85.8\%). The associated severe handicaps included: mental plus motor handicaps (eight cases, 3.5\%), motor disorders (five cases, $2.2 \%$ ), autism or psychosis (seven cases, $3.1 \%$ ), malformations (10 cases, $4.4 \%$ ), or bilateral blindness (two cases, $0.9 \%$ ).

Nine children over 8 years of age on first registration with the CDES were excluded from the prevalence calculations. Prevalence was thus determined for the 217 children residing in the three departments, which included 125 also born therein

The prevalence of bilateral severe and profound hearing loss for the 10 year period was 0.66 per 1000 residing children and 0.54 per 1000 children born and residing in the three departments. There was no statistically significant difference between the departments for either value of prevalence, although differences were greater for the prevalence of resident children. However, there was a statistically significant difference $(p<0.05)$ between the two values of prevalence for the HauteGaronne department (table 1).

There were fluctuations but no significant fall in overall prevalence over the study period.

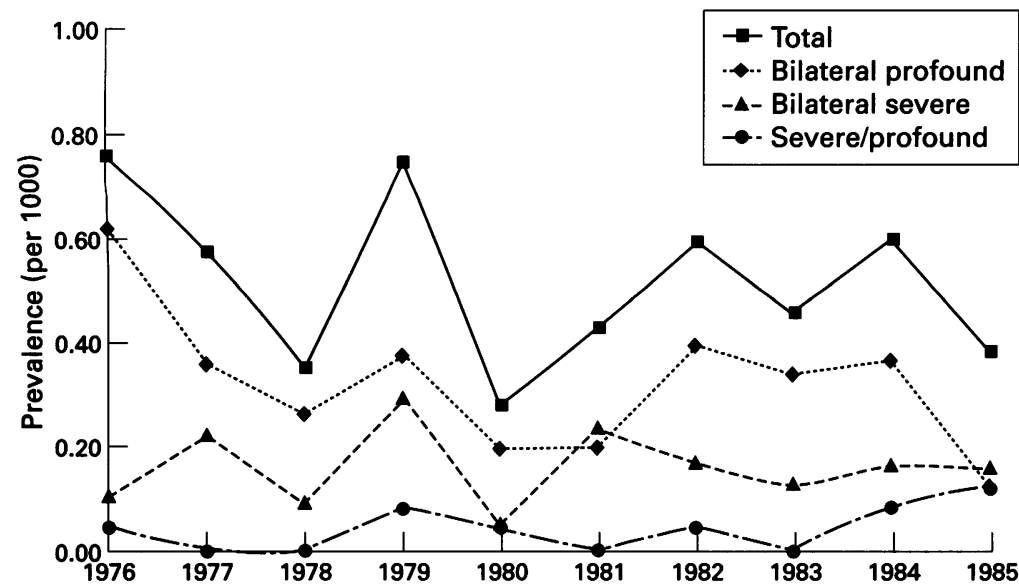

Figure 1 Prevalence of hearing loss of different degrees of severity per 1000 children less than 9 years of age born and residing in the three departments over the 10 year study period.
Bilateral profound deficits (hearing loss $>90 \mathrm{~dB}$ ) were more common than the bilateral severe deficits (hearing loss 71-90 dB), with overall prevalences of 0.39 per 1000 and 0.20 per 1000 resident children and 0.33 per 1000 and 0.16 per 1000 born and resident children, respectively. The prevalence of asymmetric deficits (severe on one side and profound on the other) was 0.07 per 1000 resident children and 0.04 per 1000 born and resident children. These prevalences did not alter significantly over the 10 year study period (fig 1 ).

A hereditary origin (hearing loss in parents or siblings) was found in $20.8 \%$ of cases. Among the cases of hereditary hearing loss, one was associated with a severe pathology (psychosis). The prevalence of hereditary hearing loss was 0.14 per 1000 resident children and 0.10 per 1000 born and resident children. Infectious aetiologies were found in 26 cases $(11.5 \%)$, including seven cases of rubella infection, one cytomegalovirus infection, and two undefined fetopathies, three cases of neonatal meningitis, and 13 cases of postnatal meningitis. In 26 other cases $(11.5 \%)$ there was a perinatal risk factor (low birth weight, premature birth, fetal distress, or admission in a specialised neonatal unit), although the cause of the hearing loss could not be attributed to these factors beyond doubt. In $31.0 \%$ of cases, the hearing loss was recorded as being congenital, with no additional specified malformation or hereditary factor. The origin was specified as unknown in $25.2 \%$ of cases.

Independence was defined by the ability to communicate (verbal or non-verbal communication), mobility (sitting, rising, walking), and the ability to carry out daily routine activities (eating, dressing, and so on). All the children had major speech difficulties, but those with no other associated pathology were relatively independent in their daily life. The eight children with associated motor and mental deficits were poorly mobile or bedridden. Five out of the 24 children whose hearing loss was associated with another deficit were totally dependent.

The mean age of initial registration with the CDES for the children less than 9 years of age fell significantly between 1976 and 1985 (4 years to 2 years; $r=-0.67 ; p=0.01$ ). It was lower in the children with an associated severe deficit (2.5 $v 3.5$ years for the isolated hearing deficits; $p<0.05)$, as well as in the children with bilateral profound hearing loss (3.1 years $v 4.4$ years for the bilateral severe hearing loss; 
$p<0.01)$. There were no significant differences between the three departments.

The care arrangements differ according to the associated impairment and severity of hearing loss. A greater proportion of the children were given speech therapy and training in sign language in specialist centres $(60 \%)$ than as outpatients $(40 \%)$. The children with a sole hearing deficit were more commonly treated as outpatients than those with an associated severe pathology $(42 \% v 23 \%$; $\mathrm{p}<0.05)$. For those with sole hearing loss, the type of care was related to the degree of severity of the condition: the children with bilateral severe hearing loss were more commonly treated as outpatients than those with bilateral profound hearing loss $(50 \% v 30 \%$; $\mathrm{p}<0.01)$.

Out of the 135 children treated in a specialist centre, the majority were placed in centres for treatment of sensory deficits $(92.0 \%)$. The other children were placed in centres for the treatment of motor deficits $(1.5 \%)$ or mental retardation $(6.0 \%)$, or centres specialising in behaviour and personality disorders $(0.5 \%)$.

For the 112 children over 6 years of age being educated either in kindergarten or primary school, we evaluated the difference in scholastic achievement from the norm. Normal achievement was found only in $36 \%$ of cases (one year behind being taken as normal). Thirty six percent of the children were two years behind the norm, and $28 \%$ were more than two years behind. The degree of underachievement was related to the associated impairment $(p<0.001)$ and was most marked for the children with motor and mental handicap (more than four years behind in two out of four cases) or psychic disorders (more than two years behind in five out of six cases). In the cases in which the hearing loss was the sole disorder, scholastic achievement did not appear to be related to the severity of the deficit. However, there was a relation between achievement and type of care, the children more than two years behind being more likely to be treated in specialised centres than children with normal scholastic achievement $(80 \% v$ $50 \% ; \mathrm{p}<0.01)$. Scholastic achievement did not appear to be related to age at first treatment (3.4 years on average for the underachievers, versus 3.3 years for the others).

\section{Discussion}

There was a slight male predominance in our population, as in most other studies. ${ }^{10}$ The origin of the difference in sex distribution of hearing loss is not known, but it does not appear to stem from a genetic factor. ${ }^{10}$

The prevalence of bilateral severe and profound hearing loss, defined as a loss of more than $70 \mathrm{~dB}$ in the best ear, was 0.66 per 1000 resident children and 0.54 per 1000 for the children born and residing in the three French departments studied. The difference in these rates was due to the difference in the Haute-Garonne department (table 1). The proportion of handicapped children residing in this department and born outside it was much higher than in the general population $(54 \% v$ $27 \%$; $<0.001$ ), whereas rates were compara- ble in the other two departments (38\% v 33\% in Isère and $28 \% v 25 \%$ in Saône et Loire). This shift of population in Haute-Garonne, which appeared to be constant over the study period, is probably due to the larger number of facilities for the care of hearing impaired children in this department. This produced an overestimate of the prevalence per thousand resident children.

Our results are close to those reported by other workers. Pabla et al found a prevalence of 0.55 per 1000 live births in children from 1 month to 3.5 years of age with a hearing loss of $80 \mathrm{~dB}$ or more. For the Oxford Handicap Register, ${ }^{1}$ the prevalence of hearing loss of $>70$ $\mathrm{dB}$ in 5 year old children was 0.51 per 1000 births. In a study of a cohort of 15 year old children with a hearing loss of more than $60 \mathrm{~dB}$ in the best ear, a prevalence of 0.44 per 1000 births has been reported. ${ }^{4}$ Watkin ${ }^{6}$ found the highest prevalence $(0.4$ per 1000 live births for bilateral hearing loss between 71 and $95 \mathrm{~dB}$ and 0.7 per 1000 for hearing loss of more than $95 \mathrm{~dB}$ ), giving an overall prevalence of 1.1 per 1000 for children aged between 1 and 16 years in a population of children of low socioeconomic status.

In the previous INSERM survey ${ }^{8}$ of three generations of children (1972, 1976, and 1981) less than 9 years of age, a prevalence of 0.72 per 1000 resident children was found for hearing loss of more than $55 \mathrm{~dB}$ and 0.49 per 1000 for hearing loss of more than $91 \mathrm{~dB}$. In view of the difference in thresholds of hearing loss, we could only compare our results for the children with profound hearing loss. The difference between our findings and those of the INSERM survey $(0.39$ per $1000 v 0.49$ per $1000 ; \mathrm{p}<0.05)$ should be interpreted with caution as they were carried out in different regions of France. Furthermore, in the INSERM survey, ${ }^{8}$ prevalence remained constant between 1972 and 1976, but fell significantly between 1976 (0.53 per 1000) and 1981 (0.36 per 1000). We did not find any decrease in prevalence in the 10 year period of our study (1976-1985).

The aetiology of hearing loss is often difficult to identify, and the findings in published reports are often conflicting. A family history of hearing loss was found in $20.8 \%$ of the children in our population, which was identical to that of the Oxford Registry (20.4\%), ${ }^{1}$ and close to that reported by Pabla et al (17.4\%), ${ }^{7}$, but lower than that reported by Thiringer et al $(39 \%) .{ }^{3}$ We found an infectious cause in $11.5 \%$ of cases, of which $38 \%$ were antenatal. These percentages are comparable to those found by other workers. ${ }^{13711}$ Perinatal events are often mentioned as factors of hearing loss, but direct evidence is usually lacking. Perinatal risk factors, however, were found in $11.5 \%$ of our population. In other studies, the proportion of perinatal aetiologies ranged from $9 \%$ to $20 \%$. $^{3711}$ The Oxford Registry, which only mentioned proven aetiologies and thus reported a high percentage of doubtful aetiologies $(54.6 \%)$, did not list any case of perinatal aetiology but observed a significant relation between low birth weight and hearing loss. ${ }^{12}$ 
Our population of children was all fairly independent, due to the large proportion of cases with a sole deficit of hearing loss. We found that the greater the number of associated conditions the lower the independence of the child. This was often the result of the associated condition rather than the hearing loss per se, despite the considerable difficulties in oral communication of the hearing impaired children.

The majority of the children with severe and profound hearing loss in our population were cared for in specialised centres, which can be accounted for by the severity of their deficit. The hearing loss was accompanied by marked speech disorders requiring intensive speech therapy and learning sign language, along with disorders in the development of cognitive faculties. These difficulties in oral communication and learning make ordinary schooling impractical. Specialised education is required either in an appropriate centre or as part of the normal school programme. The choice between these two alternatives is governed by the degree of underachievement and the severity of the hearing loss. A child with severe hearing loss may well be able to attend normal school, whereas a child with profound hearing loss will usually require specialised schooling unless the home and normal educational environments are particularly favourable. ${ }^{13}$

In view of the particular care facilities required, we analysed the cases for which the hearing loss was associated with a severe handicap. In many cases, care in a specialised centre is justified in view of the extent of the associated impairment. The type of centre selected will clearly depend on the type of associated pathology, which may often be more incapacitating than the hearing loss per se.

We noted a marked scholastic underachievement in our population, with a third being two years behind normal children of the same age and only a third keeping up with their normal contemporaries. We analysed educational attainments only up to primary school level, but it would be of great interest to have information on the later careers of these children and adolescents.

Various investigators ${ }^{14}{ }^{15}$ have pointed out the importance of an early diagnosis of hearing loss, preferably within the first year of life, in order to instigate appropriate treatment and schooling. The average age of first registration with the CDES fell from age 4 to age 2 over the 10 year study period. In view of the severity of the hearing loss in our population, the date of registration by the CDES was probably close to that of the diagnosis. The decrease in age of registration for care thus stemmed most probably from an earlier detection of the deficit. Watkin ${ }^{6}$ reported a decrease in age of detection of severe or profound hearing loss $(>70 \mathrm{~dB}$ ) from 31 months to 12 months between 1973 and 1987. Early training over the first few months of life is crucial for acquisition of speech and the social and educational future of these children. ${ }^{14}{ }^{15} \mathrm{We}$ did not, however, find any relation between age of detection of the hearing loss and scholastic achievement. This could have been due to the fact that although the age of detection fell over the study period it was still too late to be of much benefit. It was higher than that of the population studied by Watkin. ${ }^{6}$ In a study of hearing impaired schoolchildren with attentional and behavioural disorders, Kelly et $a l^{16}$ found that the children with hereditary conditions showed fewer disturbances than those with non-hereditary hearing loss. This was attributed to the earlier diagnosis and treatment of the children with hereditary disorders. The importance of early detection for improving the long term consequences of hearing deficits has prompted to advise systematic neonatal detection of hearing loss. ${ }^{14}{ }^{17}$ In France as well as in most European countries detection is only applied to children at risk. ${ }^{18}$ Nevertheless, it has been shown that risk factors identifiable in the neonatal period $^{12}{ }^{19}$ are found only in $30 \%$ to $40 \%$ of children with hearing loss. This indicates that to be effective, all children should be screened for hearing loss at birth. ${ }^{14} 17$ Earlier diagnosis should also help clear up uncertainties about the cause of the hearing loss, especially by establishing a perinatal infectious origin, which cannot be readily determined retrospectively.

This study was carried out within the framework of a public health network of INSERM, thanks to financing by INSERM the Ministry of Health, and the Caisse Medicale. It benefitted from the cooperation of the CDES, the day hospitals, and the CAMPS, to all of which we give warm thanks.

1 Oxford Register of Early Childhood Impairments. Annual report. Oxford: Level 3, Women's Centre, Oxford Radcliffe report. Oxford:

2 Cans C, Baille M-F, Jouk PS. Comment enregistrer les déficiences de l'enfant? Différentes méthodologies, intérêts et applications. Arch Pédiatr 1994;1:1144-52.

3 Thiringer K, Kankkunen A, Liden G, Niklasson A. Perinatal risk factors in the aetiology of hearing loss in preschoo children. Dev Med Child Neurol 1984;26:799-807.

4 Sorri M, Rantakallio P. Prevalence of hearing loss at the age of 15 in a birth cohort of 12000 children from Northern Finland. Scand Audiol 1985;14:203-7.

5 Rantakallio P. The longitudinal study of the Northen Finland birth cohort of 1966. Pediatr Perinat Epidemio 1988;2:59-88.

6 Watkin PM. The age of identification of childhood hearing loss-improvements since the 1970s. Public Health 1991; 105:303-12.

7 Pabla HS, McCornmick B, Gibbin KP. Retrospective study of the prevalence of bilateral sensorineural deafness in childhood. Int $¥$ Pediatr Otorhinolaryngol 1991;22:161-5.

8 Rumeau-Rouquette C, du Mazaubrun C, Verrier A, Mlika A. Prévalence des handicaps. Evolution dans trois génération d'enfants 1972, 1976, 1981. Paris: INSERM, 1994.

9 World Health Organisation. International Classification of impairments, disabilities and handicaps; a manual of classification relating to the conséquences of disease. Geneva: WHO, 1980.

10 Cremers CWRJ, Van Rijn PM, Huygen PLM. The sex-ratio in childhood deafness, an analysis of the male predominance. Int $\mathcal{Y}$ Pediatr Otorhinolaryngol 1994;30:105-10.

11 Delvaux de Fenffe J, Deggouj N, Dutilleux D, Gersdorff $M$. Etiologie des surdités chez les enfants. Acta Oto-Laryngol Belg 1992;46:375-80

12 Johnson A, Ashurst $H$. Screening for sensorineural deafness by health visitors. Arch Dis Child 1990;65:841-5.

13 Pasche P, Dutoit-Marco M-L. Devenir scolaire de l'enfant déficient auditif sévère et profond. Méd Hyg 1987; déficient a

14 Bonfils $P$, François $M$, Aidan D, et al. La surdité en période néonatale: les bases du dépistage. Arch Pédiatr 1995;2:685-91.

15 Dussert J. Quelques aspects de l'éducation auditive précoce chez l'enfant sourd. Revue Laryngol 1988;109:253-6.

16 Kelly DP, Kelly BJ, Jones ML, Moulton NJ, Verhulst SJ, Bell SA. Attention deficits in children and adolescents with hearing loss. A survey. Am $\mathcal{F}$ Dis Child 1993;147:737-41.

17 National Institutes of Health. Early identification of hearing impairment in infants and young children. NIH Consensus Statement 1993;11:1-25.

18 Francois $\mathrm{M}$, Bonfils $\mathrm{P}$, Narcy $\mathrm{Ph}$. Screening for neonatal and infant deafness in Europe in 1992. Int $\mathcal{f}$ Pediat Otorhinolaryngol 1995;31:175-82.

19 Watkin PM, Baldwin M McEnery G Neonatal at risk screening and the identification of deafness. Arch Dis Child $1991 ; 66: 1130-5$. 